\title{
Fighting food temptations: The modulating effects of short-term cognitive reappraisal, suppression and up- regulation on mesocorticolimbic activity related to appetitive motivation
}

Citation for published version (APA):

Siep, N., Roefs, A. J., Roebroeck, A. F., Havermans, R. C., Bonte, M. L., \& Jansen, A. T. M. (2012). Fighting food temptations: The modulating effects of short-term cognitive reappraisal, suppression and upregulation on mesocorticolimbic activity related to appetitive motivation. Neuroimage, 60(1), 213-220. https://doi.org/10.1016/j.neuroimage.2011.12.067

Document status and date:

Published: 01/03/2012

DOI:

10.1016/j.neuroimage.2011.12.067

Document Version:

Publisher's PDF, also known as Version of record

Document license:

Taverne

Please check the document version of this publication:

- A submitted manuscript is the version of the article upon submission and before peer-review. There can be important differences between the submitted version and the official published version of record. People interested in the research are advised to contact the author for the final version of the publication, or visit the DOI to the publisher's website.

- The final author version and the galley proof are versions of the publication after peer review.

- The final published version features the final layout of the paper including the volume, issue and page numbers.

Link to publication

\footnotetext{
General rights rights.

- You may freely distribute the URL identifying the publication in the public portal. please follow below link for the End User Agreement:

www.umlib.nl/taverne-license

Take down policy

If you believe that this document breaches copyright please contact us at:

repository@maastrichtuniversity.nl

providing details and we will investigate your claim.
}

Copyright and moral rights for the publications made accessible in the public portal are retained by the authors and/or other copyright owners and it is a condition of accessing publications that users recognise and abide by the legal requirements associated with these

- Users may download and print one copy of any publication from the public portal for the purpose of private study or research.

- You may not further distribute the material or use it for any profit-making activity or commercial gain

If the publication is distributed under the terms of Article 25fa of the Dutch Copyright Act, indicated by the "Taverne" license above,

Download date: 26 Apr. 2023 


\title{
Fighting food temptations: The modulating effects of short-term cognitive reappraisal, suppression and up-regulation on mesocorticolimbic activity related to appetitive motivation
}

\author{
Nicolette Siep ${ }^{\mathrm{a}, *}$, Anne Roefs ${ }^{\mathrm{a}}$, Alard Roebroeck ${ }^{\mathrm{b}}$, Remco Havermans ${ }^{\mathrm{a}}$, Milene Bonte ${ }^{\mathrm{b}}$, Anita Jansen ${ }^{\mathrm{a}}$ \\ a Department of Clinical Psychological Science, Faculty of Psychology and Neuroscience, Maastricht University, P.O. Box 616, 6200 MD Maastricht, The Netherlands \\ ${ }^{\mathrm{b}}$ Department of Cognitive Neuroscience, Faculty of Psychology and Neuroscience, Maastricht University, P.O. Box 616, 6200 MD Maastricht, The Netherlands
}

\section{A R T I C L E I N F O}

\section{Article history:}

Received 15 February 2011

Revised 6 December 2011

Accepted 22 December 2011

Available online 31 December 2011

\section{Keywords:}

fMRI

Cognitive control strategies

Reward

Suppression

Reappraisal

Up-regulation

\begin{abstract}
A B S T R A C T
The premise of cognitive therapy is that one can overcome the irresistible temptation of highly palatable foods by actively restructuring the way one thinks about food. Testing this idea, participants in the present study were instructed to passively view foods, up-regulate food palatability thoughts, apply cognitive reappraisal (e.g., thinking about health consequences), or suppress food palatability thoughts and cravings. We examined whether these strategies affect self-reported food craving and mesocorticolimbic activity as assessed by functional magnetic resonance imaging. It was hypothesized that cognitive reappraisal would most effectively inhibit the mesocorticolimbic activity and associated food craving as compared to suppression. In addition, it was hypothesized that suppression would lead to more prefrontal cortex activity, reflecting the use of more control resources, as compared to cognitive reappraisal. Self-report results indicated that up-regulation increased food craving compared to the other two conditions, but that there was no difference in craving between the suppression and cognitive reappraisal strategy. Corroborating self-report results, the neuroimaging results showed that up-regulation increased activity in important regions of the mesocorticolimbic circuitry, including the ventral tegmental area, ventral striatum, operculum, posterior insular gyrus, medial orbitofrontal cortex and ventromedial prefrontal cortex. Contrary to our hypothesis, suppression more effectively decreased activity in the core of the mesocorticolimbic circuitry (i.e., ventral tegmental area and ventral striatum) compared to cognitive reappraisal. Overall, the results support the contention that appetitive motivation can be modulated by the application of short-term cognitive control strategies.
\end{abstract}

(C) 2012 Elsevier Inc. All rights reserved.

\section{Introduction}

In most industrialized societies, where food is plenty, people often find themselves eating in the absence of any real hunger and all too often beyond direct energy requirements. This type of eating behavior is thought to be the result of a strong appetitive motivation, which has been linked to activation of the mesocorticolimbic pathway (Alcaro et al., 2007; Kelley and Berridge, 2002). This excessive appetite for particularly palatable high calorie foods would undoubtedly lead to weight gain in the absence of some kind of control. Researchers have therefore proposed that eating behavior is the outcome of an interplay between appetitive motivation and inhibitory cognitive control (Appelhans, 2009; Nederkoorn et al., 2006, 2010).

The suggestion that cognitive control can modulate appetitive motivation is in line with current cognitive interventions for obesity, which propose that food cravings can be successfully decreased by actively controlling the way one thinks about foods (Beck, 2007;

\footnotetext{
* Corresponding author. Fax: + 31433884196.

E-mail address: Nicolette.Siep@maastrichtuniversity.nl (N. Siep).
}

Stephens, 2007; Werrij et al., 2009a, 2009b). If so, given that appetitive motivation is associated with mesocorticolimbic activity, one would expect that cognitive restructuring - the aim of cognitive therapy - would modulate this activity. There is some indirect evidence for the influence of cognitive control on brain activity within the mesocorticolimbic circuitry. For example, previous neuroimaging studies show that word-level cognitive labels of odors and flavors can modulate activity in the orbitofrontal cortex (OFC; de Araujo et al., 2005; Grabenhorst et al., 2008), and that deliberate suppression of hunger feelings inhibits activity in mesocorticolimbic regions such as the amygdala, the hippocampus, the insula, the OFC, and striatum (Wang et al., 2009). In addition, in a previous study (Siep et al., 2009) increased mesocorticolimbic activity was only found when the task required participants to attend to the palatable taste, smell and texture of a presented visual food cue, but not when they were required to attend to a neutral aspect of the same food cue. These few studies suggest that it is possible that by the way one thinks of a food or the manner in which one deliberately tries to perceive a given food affects mesocorticolimbic activity. As mesocorticolimbic activity is related to appetitive motivation, this in turn might influence how much food is eaten. 
Previous research has identified three types of short-term cognitive control strategies that are known to modulate emotional responses (Gross, 2006); (1) up-regulation, which increases the intensity of prepotent responses, (2) cognitive reappraisal, which changes the way one thinks about emotion-eliciting cues in a way that changes its emotional impact and (3) suppression, which is related to both the active inhibition of thoughts (Wenzlaff and Wegner, 2000) and emotional responses (Gross, 2006). Neuroimaging studies examining the neural bases of up-regulation, cognitive reappraisal and suppression, have found that each strategy differs in the way it influences brain activity in the mesocorticolimbic circuitry. For example, up-regulating negative emotions increases medial prefrontal cortex (PFC) and decreases amygdala activity (Ochsner et al., 2004), while decreasing negative emotion by cognitive reappraisal increases activity in the lateral ventral and orbital PFC and decreases activity in the amygdala, ventral striatum and insula (Ochsner et al., 2004; Wager et al., 2008). In addition, research indicates that suppression and cognitive reappraisal differ in their effects, showing that suppression increases PFC activity, but also increases amygdala and insula responses (Goldin et al., 2008). Taken together, these results show that cognitive strategies are effective in modulating mesocorticolimbic activity involved in emotion processing and suggest that they might also be effective in regulating appetitive motivation.

To further investigate the hypothesized interaction between appetitive motivation and cognitive control, the present functional magnetic neuroimaging (fMRI) study investigates the effects of shortterm suppression, cognitive-reappraisal and up-regulation strategies on subjective experiences of food craving and mesocorticolimbic activity in healthy women. Participants were instructed to look at palatable food pictures and 1) imagine the food's palatable smell, texture and taste (i.e., up-regulation), 2) immediately inhibit any thoughts concerning food palatability and/or food cravings (i.e., suppression), or 3 ) focus on alternative meanings of the presented food cues, for example, the longer term consequences of consuming the food for their health (i.e., cognitive reappraisal). We hypothesized that selfreported food cravings would be higher following the up-regulation strategy, as compared to suppression and cognitive reappraisal. Furthermore, it was hypothesized that the cognitive reappraisal strategy would result in lower self-reported food craving as compared to suppression. Concerning the neuroimaging data, it is expected that activity in mesocorticolimbic regions will be increased by up-regulation compared to both suppression and cognitive reappraisal and that cognitive reappraisal will be more effective in decreasing mesocorticolimbic activity as compared to suppression. Lastly, in line with previous findings suggesting that suppression requires more control resources (Goldin et al., 2008), we hypothesized that suppression would result in larger increases in PFC activity as compared to cognitive reappraisal.

\section{Method}

\section{Participants}

Undergraduate students were recruited using flyers posted at Maastricht University. Given that women more often engage in nutritional self-assessments and dieting behavior than men do (Davy et al., 2006; Morse and Driskell, 2009), only women were invited for an interview. In this interview height, weight, age, handedness, medication use, (family) history of eating disorders and other psychiatric disorders, dietary restrictions, impulsivity, and reward responsiveness were assessed. Candidates were excluded from participation when they disliked more than four of the foods used as stimuli in this study. Selected participants were 14 right-handed, non-dieting, healthy students with a healthy body weight (body mass index (BMI) between 18.5 and $25[M=21.5, S D=1.9]$ ), and a score of $<15$ on the Restraint Scale $(M=10.7, S D=1.9$; Herman et al., 1978), with a mean age of $21.1(S D=1.5)$. Because food intake varies across the menstrual cycle in females (Bryant et al., 2006), participants were selected based on the use of monophasic Combined Oral Contraceptives (COCs). Monophasic COCs inhibit the production of fertility hormones and consequently prevent increases in food intake in the premenstrual phase (Goldzieher, 1994). Further, because the personality characteristics of impulsivity and reward responsiveness are supposed to reflect the sensitivity of the reward system (Davis et al., 2007), participants were screened on reward responsiveness and impulsivity. All participants scored within the normative population range of impulsivity as measured with the Barratt Impulsiveness Scale [Spinella, 2007; Impulsivity score participants: $M=59.7$, $S D=4.9$; normative score: $M=64.2, S D=10.7]$. In addition, participants scored within the normative population range of reward responsiveness as measured with a subscale from the BIS/BAS scale (Carver and White, 1994; participants' score: $M=16.7, S D=1.5$; normative score: $M=17.5, S D=1.4$ ).

\section{Stimuli}

In a pilot study, 25 savory and 25 sweet high calorie food pictures were selected as candidate stimuli from an internet database (www. istockphoto.com). Subsequently, these food pictures were rated on $100 \mathrm{~mm}$ visual analogue scales (VAS) by 20 healthy, non-dieting female volunteers not participating in the actual study on calorie content (0: very low calorie-100: very high calorie) and palatability (0: very bad tasting-100: very good tasting). Based on these ratings, 14 sweet, palatable, high calorie food pictures [calorie content ratings: $M=82.06, S D=4.84$; palatability ratings: $M=65.67, S D=6.85$; e.g., chocolate, cake, cookies, ice cream] and 14 savory, palatable, high calorie food pictures [calorie content ratings: $M=80.65, S D=4.61$; palatability ratings: $M=67.20, S D=4.61$; e.g., pizza, fries, crisps, hamburger] were selected. The selected food pictures were projected as pop-out figures on a black canvas to minimize noise input (Rainer et al., 2001). For a more elaborate discussion on pop-out figures and the use of pictures instead of real foods, we refer to a previous fMRI study (Siep et al., 2009). Only pictures of high calorie foods were included, as we assume that healthy, lean women apply cognitive control strategies mainly to high calorie foods and not so much to low calorie foods.

\section{Design and experimental task}

This study used a one-way within-subjects design with four levels (cognitive control strategy: cognitive reappraisal, suppression, upregulation, and passive viewing). To avoid carry-over effects from the cognitive control conditions to the passive viewing condition, all participants started the experiment with a passive viewing task. In the passive viewing task, pictures of food were pseudo-randomly presented in the center of the screen. To ensure that the participant maintained a constant level of attention, she was instructed to press a button with her right index finger as soon as a dot appeared in the center of a food picture. Dots appeared in $13 \%$ of the food picture trials and were later removed from analyses.

The passive viewing task was followed by a practice task to familiarize the participant with the cognitive control conditions and the symbols representing the conditions: eye, stop sign, and upward arrow (see Fig. 1 for an overview). Training of the participant included initial instructions, followed by practice as the investigator observed and shaped her technique. The participant was specifically instructed not to look away from the images, or to close her eyes. The eye symbol indicated that the participant should think about the negative consequences of eating the presented food for her weight, health, and bodily appearance (i.e., cognitive reappraisal). This type of reappraisal has also been referred to as situationfocused reappraisal (Ochsner et al., 2004), in which the participant 

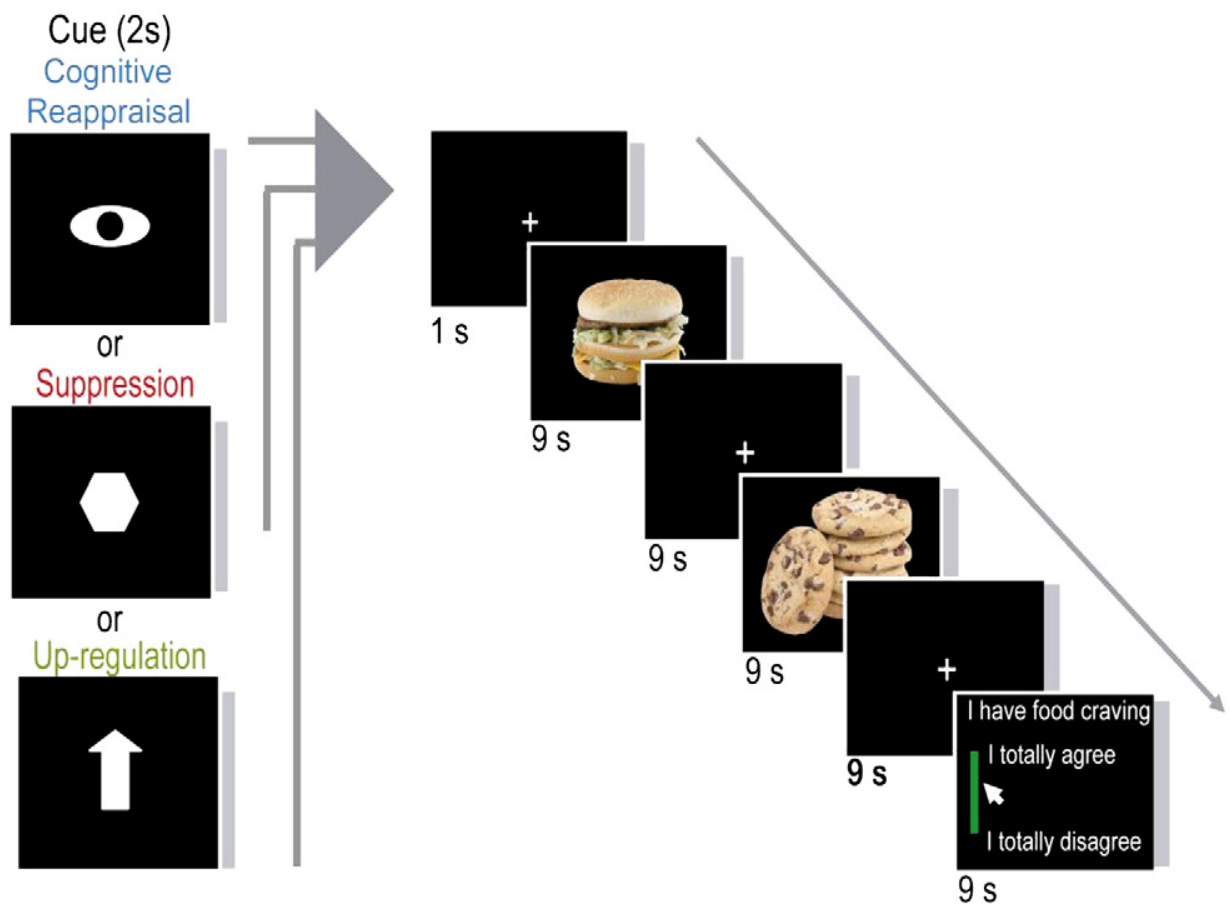

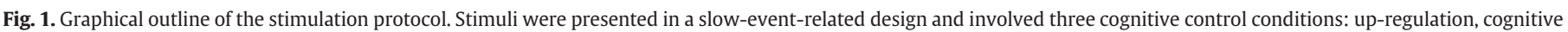

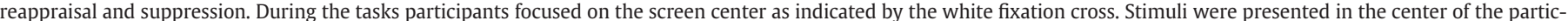
ipants' visual field. At the beginning of each block a cue was presented indicating the task.

has to re-interpret the actions and outcomes for a given image. The stop sign indicated that the participant should look at the presented food cue in a neutral way and immediately inhibit any thoughts (Wenzlaff and Wegner, 2000) or cravings, which can also be behavioral, (Gross, 2006) related to the palatability of the presented food, without looking away from the picture (i.e., suppression). The upward arrow indicated that the participant should increase their cravings for the presented food cues by actively thinking about the delicious smell, taste, and texture of the presented food cue in a way that would make her mouth water (i.e., up-regulation).

Once the participant had mastered the technique to the satisfaction of the experimenter, two experimental runs followed in which the participant applied the cognitive control strategies. In these two runs, the participant was always first shown the symbol, cueing which type of cognitive control strategy she should apply. To make the application of the three cognitive control strategies less difficult and confusing, two food pictures were presented sequentially, during which the participant applied the same cognitive strategy. The presentation of the two food pictures was followed by a vertical $100 \mathrm{~mm}$ VAS, assessing experienced craving (item: "I have cravings for one or more specific foods", top: I totally agree (100)-bottom: I totally disagree $(0)$ ). This item was taken from the Food Craving Questionnaire (Moreno et al., 2008).

\section{Stimulation protocol}

The experiment consisted of a total of three experimental runs in which food pictures were presented in a slow event-related fashion, and one anatomical scan. During the passive viewing run, the presentation of each food picture trial lasted $9 \mathrm{~s}$, followed by a white fixation cross ( $9 \mathrm{~s}$ ). In four of the food picture trials a white dot appeared for $200 \mathrm{~ms}$ after a variable time length from the first presentation of the food picture. The participant was instructed that fixation should be maintained throughout the passive viewing run. In total, the passive viewing run lasted approximately $9 \mathrm{~min}$. For each participant, the order of the 14 savory and 14 sweet food pictures within the passive viewing run was randomized and comprised 32 trials including the 4 "dot trials". Identical pictures were presented in all conditions and each picture was presented once per condition.

In the two cognitive control runs, each cognitive control strategy was presented 7 times in a pseudo-randomized order. During each type of cognitive control condition (see Fig. 1), an initial cue appeared $(2 \mathrm{~s})$, indicating which cognitive control strategy the participant should apply, followed by a white fixation cross $(1 \mathrm{~s})$. Then two food picture trials were presented sequentially, lasting $9 \mathrm{~s}$ each, followed by fixation $(9 \mathrm{~s})$. Presentation of the two food pictures was followed by a VAS ( $9 \mathrm{~s}$ ). Although the duration of the VAS trial remained constant, the VAS disappeared as soon as the participant made her choice. Throughout one cognitive control run, each condition was repeated seven times. Each cognitive control run lasted approximately 20 min.

The order of the three cognitive control conditions was randomized per run and then manually checked for repetitions to avoid fMRI adaptation effects (Grill-Spector and Malach, 2001). For each participant, the order of food stimuli per condition, within each run, was fully randomized. The order of the two cognitive control runs was balanced across participants. The total fMRI session lasted $75 \mathrm{~min}$.

\section{Procedure}

All imaging sessions took place around lunch-time (i.e., between 1 and $3 \mathrm{pm}$ ). Participants were instructed not to consume any food or beverages (except water) four hours prior to the imaging session. Upon arrival, written informed consent and ethical approval were obtained from the participant. Next, hunger was assessed with $100 \mathrm{~mm}$ VAS (Friedman et al., 1999; translated into Dutch), which showed that participants were moderately hungry at the start of the fMRI experiment $[M=48.7, S D=19.53]$. After completing the questionnaire, the participant entered the scanner. The participant did not receive any instructions about the different experimental tasks, to avoid influences from the cognitive control instructions on the passive viewing task. After completion of the passive viewing task, an anatomical scan was performed during which the participant received 
the instructions for the cognitive control tasks. Once the participants had mastered the different techniques to satisfaction of the researcher, two experimental runs were presented in which the participant applied the practiced cognitive control techniques. At the end of the fMRI session, the participant completed an exit questionnaire inquiring about the strategies she applied during the cognitive control conditions and the experienced difficulties. After completing the study, the participant received $€ 15$ compensation.

\section{fMRI data acquisition}

Images were acquired with a $3 \mathrm{~T}$ Siemens Magnetom Allegra Head-only Scanner at the Maastricht Brain Imaging Centre (MBIC) using a birdcage volume coil. Gradient-echo planar imaging (EPI) volumes were acquired ( 50 slices, $\mathrm{TR}=3000 \mathrm{~ms}$ ). Imaging parameters were optimized to minimize susceptibility and distortion artifacts in the OFC (see: Weiskopf et al., 2006). The relevant factors included oblique axial imaging with a negative (i.e., backward) tilt angle of $30^{\circ}$, minimizing voxel size $(2 \times 2 \times 2.5 \mathrm{~mm})$ in the plane of imaging, a short echo time of $25 \mathrm{~ms}$, and a high imaging bandwidth $(2790 \mathrm{~Hz}$ over the field of view, echo spacing $=0.4 \mathrm{~ms}$ ). The voxel matrix size was $128 \times 104 \mathrm{~mm}$, and the field of view (FoV) was $256 \times 208 \mathrm{~mm}$. Acquisition of functional images yielded 200 volumes during the passive run and 409 during each cognitive modulation run. One highresolution whole-brain anatomical T1-weighted scan was acquired: an optimized MPRAGE sequence $(T R=2250 \mathrm{~ms}$, $T E=2.6 \mathrm{~ms}$, flip angle $=9^{\circ}, 1 \times 1 \times 1 \mathrm{~mm}$ ).

\section{fMRI data preprocessing}

All processing and analyses of the fMRI data were performed using BrainVoyager QX version 1.9 (Brain Innovations, Maastricht, The Netherlands). The first two volumes of the $\mathrm{T} 2 *$ weighted functional images were discarded due to magnetic saturation effects. Preprocessing comprised slice scan timing correction (using sinc interpolation), motion correction (using a 3D rigid-body transformation of each volume to the first volume of each run and using sinc interpolation) and high-pass filtering to remove low-frequency noise (up to 3 cycles in the single run time-course). Individual functional data were smoothed using a $6 \mathrm{~mm}$ full-width-at-half-maximum isotropic Gaussian Kernel. The anatomical scan and the functional data were then spatially normalized using Talairach transformation procedures (Talairach and Tournoux, 1988). For group analysis, the normalized individual functional data were averaged accounting for both scanto-scan and participant-to-participant variability.

\section{fMRI analysis}

A whole-brain, voxel-wise Random Effects (RFX) ANOVA was used to test for differences in BOLD signal across cognitive control strategies. Because our hypothesis concerned the modulation of mesocorticolimbic activity by the three modulation conditions, only the suppression, cognitive reappraisal, and up-regulation conditions were included at this stage of the analysis.

For the resulting F-map of the RFX ANOVA, F-test main effect of cognitive control strategy, a significance level of $p<0.01$ was used. To correct for multiple comparisons, a minimum cluster size of 9 contiguous voxels was adopted (determined by a cluster size threshold estimator plug-in implemented in BrainVoyager), yielding a wholebrain corrected statistical rejection criteria of $5 \%$.

To test our three hypotheses, we used the functional region of interest (fROI) approach, which involves identifying a priori hypothesized candidate regions in the PFC and mesocorticolimbic from the corrected whole-brain F-map and then calculating the overall summary measure of response in each region (see: Saxe et al., 2006). This method allowed us to decrease the influence of noise that varies between voxels and make inferences about the response profile of each fROI as a whole, rather than particular voxels within the region.

Our corrected F-map comprised a total of 24 fROIs (Table 1), of which 14 fROIs were located in the a priori hypothesized PFC and mesocorticolimbic circuitry. The beta weights for each condition, including passive viewing, were averaged across participants and across all voxels within each of these 14 fROIs. Bar-plots were made to visualize the response profiles of all fROIs (Fig. 2). Following our hypothesis, fROIs were divided into two groups: regions located in mesocorticolimbic circuitry but outside the PFC (Fig. 2A), and regions located in the PFC (Fig. 2B). A functional region of fROI analysis was performed to evaluate differences in the magnitude of the MR signal change between conditions, using pairwise $t$-tests. $T$-tests were considered statistically significant at $\alpha=0.01$ and planned comparisons at $\alpha=0.05$. Results of these $t$-tests are depicted in Fig. 2, and are the focus of the discussion.

\section{Results}

\section{Manipulation check}

To test whether the participants followed the instructions, they were asked to describe their applied cognitive control strategies in an exit questionnaire. From these reports we concluded that all participants did indeed follow our instructions as intended, as their description matched the practice task instructions.

At the end of the fMRI session, the participants completed an exit questionnaire that contained $100 \mathrm{~mm}$ VAS questions, inquiring about experienced difficulties during scanning. One of these questions was: "What do you think of the time you spent inside the scanner?" (0: not long at all-100: much too long). Participants scored $48.79 \pm 13.86(M \pm S D)$. Another question asked whether participants were able to maintain their concentration throughout the experiment (0: not at all-100: very well). The participants scored $56.21 \pm 18.13(M \pm S D)$. Together these self-report results indicate that the impact of the scanning duration on the participants' mental state was limited and did not raise major concerns.

Table 1

Results of whole brain RFX ANOVA, F-test: main effect of cognitive control strategy.

\begin{tabular}{llllrl}
\hline Functional region of interest & $\mathrm{L} / \mathrm{R}$ & $\begin{array}{l}\text { Talairach coordinates } \\
(\mathrm{x}, \mathrm{y}, \mathrm{z})\end{array}$ & BA & F-score & $p$-value \\
\hline Anterior temporal cortex & $\mathrm{L}$ & $-43,5,-30$ & 21 & 8.48 & $<.001$ \\
Cerebellum & $\mathrm{L}$ & $-31,-81,-27$ & - & 9.32 & $<.001$ \\
Medial orbitofrontal cortex & $\mathrm{L}$ & $-12,19,-7$ & 11 & 3.33 & 0.03 \\
Inferior temporal gyrus & $\mathrm{R}$ & $58,-47,-11$ & 20 & 6.28 & 0.001 \\
Ventral tegmental area & $\mathrm{L}$ & $-5,-14,-7$ & - & 6.22 & 0.002 \\
Fusiform gyrus & $\mathrm{L}$ & $-29,-56,-15$ & 37 & 9.51 & $<.001$ \\
Anterior prefrontal cortex & $\mathrm{R}$ & $23,65,11$ & 10 & 10.06 & $<.001$ \\
& $\mathrm{~L}$ & $-22,61,17$ & 10 & 8.49 & $<.001$ \\
Ventromedial prefrontal cortex & $\mathrm{L}$ & $-9,24,-1$ & 24 & 4.74 & 0.007 \\
Lateral orbitofrontal cortex & $\mathrm{L}$ & $-46,49,4$ & 11 & 10.71 & $<.001$ \\
Ventral striatum & $\mathrm{L}$ & $-11,-2,-3$ & - & 6.22 & 0.002 \\
Parastriatal cortex & $\mathrm{R}$ & $22,-94,12$ & 18 & 9.50 & $<.001$ \\
& $\mathrm{~L}$ & $-14,-95,14$ & 18 & 7.02 & $<.001$ \\
Operculum & $\mathrm{L}$ & $-58,-19,26$ & 41 & 10.94 & $<.001$ \\
$\quad$ Posterior short insular gyrus & $\mathrm{R}$ & $73,-8,11$ & 13 & 10.71 & $<.001$ \\
& $\mathrm{~L}$ & $-38,-6,11$ & 13 & 12.33 & $<.001$ \\
Posterior cingulate cortex & $\mathrm{L}$ & $-9,-53,8$ & 30 & 8.65 & $<.001$ \\
Dorsolateral prefrontal cortex & $\mathrm{R}$ & $41,53,33$ & 9 & 10.71 & $<.001$ \\
Somatosensory cortex & $\mathrm{R}$ & $-55,-11,31$ & 3 & 11.14 & $<.001$ \\
& $\mathrm{~L}$ & $-56,-4,34$ & 3 & 10.94 & $<.001$ \\
Inferior parietal cortex & $\mathrm{R}$ & $41,-47,43$ & 40 & 4.66 & 0.007 \\
Frontal eye field & $\mathrm{R}$ & $28,-10,55$ & 6 & 3.64 & 0.02 \\
Extrastriate cortex & $\mathrm{R}$ & $17,-82,40$ & 19 & 5.08 & 0.004 \\
\hline No: & & & & &
\end{tabular}

Note: $\mathrm{L}=$ left, $\mathrm{R}=$ right, $\mathrm{BA}=$ Brodmann area; fROIs in italic. 
A
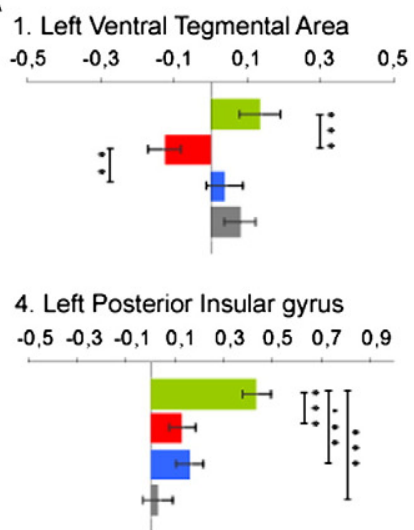

2. Left Ventral Stria:um

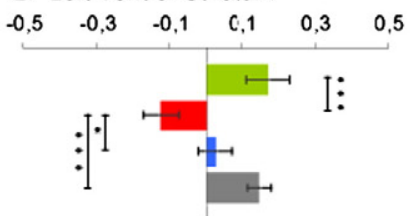

5. Right Posterior Insular Gyrus

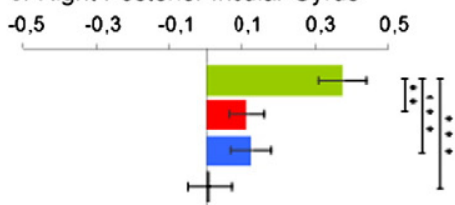

3. Left Operculum

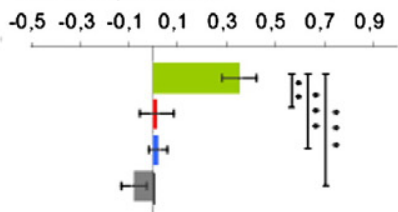

\begin{tabular}{|c|c|c|}
\hline Up-regulation & Cognitive Reappraisal & $\begin{array}{rl}* & p<.05 \\
* * & p<.01\end{array}$ \\
\hline suppression & Passive Viewing & ${ }^{* * *} p<.001$ \\
\hline
\end{tabular}
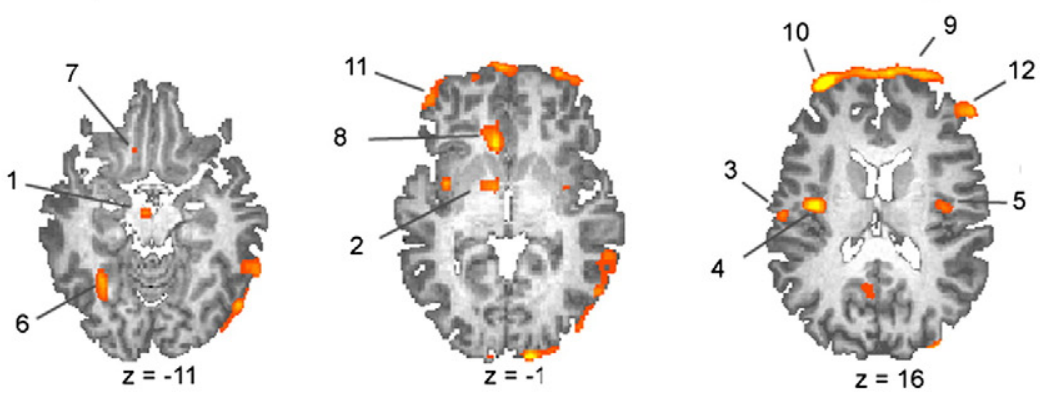

$F(2,26)$

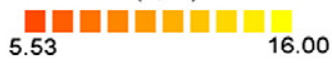

B
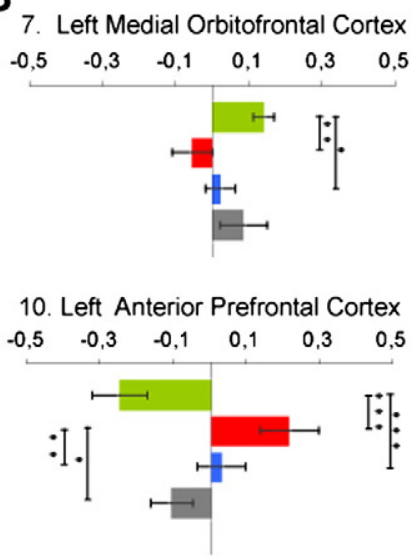

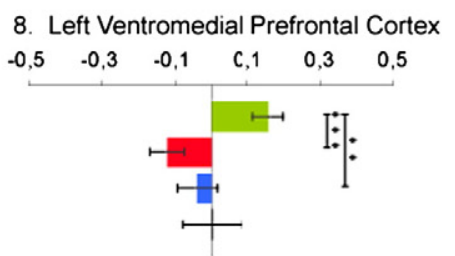

11. Left Lateral Orbitofrontal Cortex

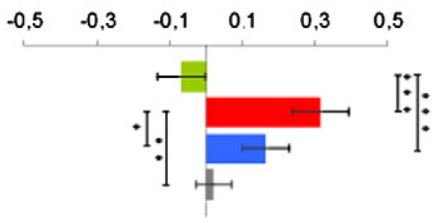

9. Right Anterior Prefrontal Cortex

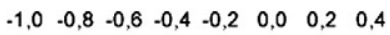

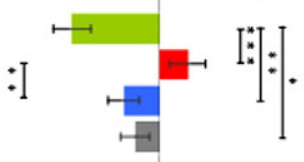

12. Right Dorsolateral Prefrontal Cortex

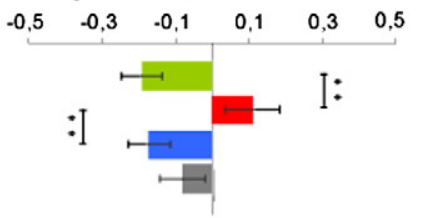

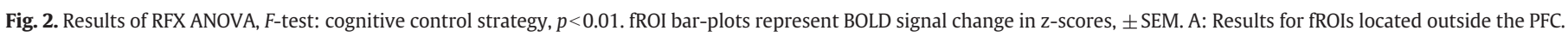
$B$ : Results for fROIs located in the PFC.

\section{Self-reported food craving}

The food craving VAS ratings during the two fMRI runs were averaged over participants, for each cognitive control strategy separately. There was a significant main effect of cognitive control strategy on experienced food craving $[F(2,26)=43.37, p<.001$; cognitive reappraisal: $M=50.06, S D=17.98$; suppression: $M=52.09, S D=18.76$; upregulation: $M=70.34, S D=18.27]$. Pairwise comparisons showed that subjective food craving after the up-regulation trials was significantly increased as compared to that following the cognitive reappraisal $(p<.001)$ and suppression $(p<.001)$ trials, which is in line with the hypothesis of increased food craving after up-regulation compared to up-regulation and suppression. In contrast to what was expected, however, subjective ratings of craving did not differ between the cognitive reappraisal trials and suppression trials $(p=.83)$.

\section{fMRI results}

The whole brain analysis of the effect of cognitive control strategy (up-regulation, suppression vs. cognitive reappraisal) on BOLD activity revealed a network of fROIs showing significant effects (Table 1). The resulting F-map included six fROIs located within the mesocorticolimbic system, including the left ventral tegmental area (VTA; 
Duzel et al., 2009), the left ventral striatum (VS; Kreitzer, 2009), the left operculum (Schweinhardt et al., 2009) and bilateral posterior insular gyrus (PIG; Craig, 2009). See Fig. 2A. In addition, six fROIs were located in the PFC: the left medial orbitofrontal cortex (OFC), the left ventromedial prefrontal cortex (vmPFC), bilateral anterior prefrontal cortex (aPFC), the left lateral orbitofrontal cortex (lOFC) and the right dorsolateral prefrontal cortex (dlPFC). See Fig. 2B.

In line with the hypothesis of increased mesocorticolimbic activity during up-regulation compared to both suppression and cognitive reappraisal, results showed that up-regulation increased activity as compared to suppression in all six mesocorticolimbic fROIs located outside the PFC [VTA: $t(13)=5.88, p<.001$; VS: $t(13)=5.47, p<.001$; operculum: $t(13)=3.39, p<.01$; left PIG: $t(13)=5.30, p<.001$; the right PIG: $t(13)=4.03, p<.01$ ] and two regions located in the PFC [mOFC: $t(13)=3.65, \quad p<.01$; vmPFC: $t(13)=6.54, p<.001$ ]. Upregulation showed increased activity as compared to cognitive reappraisal in the left operculum $[t(13)=5.55, p<.001]$, the left posterior short insular gyrus $[t(13)=5.13, p<.001]$, the right posterior short insular gyrus $[t(13)=4.48, p<.001]$. However, up-regulation did not significantly differ from cognitive reappraisal in the VTA $[t(13)=0.66$, $p=.52]$ and the left VS [ $t(13)=0.59, p=.67]$. Up-regulation did significantly increase activity as compared to cognitive reappraisal in the $\operatorname{mOFC}[t(13)=2.50, p<.05]$ and vmPFC $[t(13)=3.89, p<.01]$. In addition, results showed that the up-regulation strategy resulted in greater activity compared to passive viewing in all fROIs, except for the left VTA $[t(13)=0.43, p=.76]$ and left VS $[t(13)=0.54, p=.69]$. For the fROIs located in the PFC (Fig. 2B) results showed that upregulation significantly decreased activity in the right anterior PFC [aPFC; $t(13)=2.63, p<.05$ ] compared to passive viewing.

Surprisingly, in contrast to the second hypothesis of more successful inhibition of mesocorticolimbic activity during cognitivereappraisal compared to suppression, results showed that suppression significantly inhibited activity in the left VTA $[t(13)=3.45$, $p<.01]$ and the left ventral striatum $[t(13)=2.77, p<.05]$ relative to cognitive reappraisal. Suppression also resulted in significantly lower activity compared to passive viewing in the left VTA [ $t(13)$ $=2.93, p<.05]$ and left VS $[t(13)=4.54, p<.001]$. None of the fROIs showed a change in activity during cognitive reappraisal compared to passive viewing. These findings suggest that short-term suppression is more successful at inhibiting mesocorticolimbic activity as compared to cognitive reappraisal.

In line with the third hypothesis of increased PFC activity during suppression compared to cognitive reappraisal, results showed that suppression significantly increased activity in the right anterior PFC [aPFC; Fig. 2B; $t(13)=3.43, p<.01]$, the left aPFC $[t(13)=3.07$, $p<.01$ ], the left lateral OFC [1OFC; $t(13)=2.79, p<.05$ ], and the right dorsolateral PFC [dlPFC; $t(13)=4.49, p<.01$ ] relative to cognitive reappraisal. Suppression also significantly increased activity in the left aPFC $[t(13)=2.78, p<.05]$ and left $\operatorname{lOFC}[t(13)=3.43, p<.01]$ compared to passive viewing.

\section{Discussion}

In this study self-report measures and fMRI were used to examine the regulatory short-term effects of up-regulation, cognitive reappraisal, and suppression on mesocorticolimbic activity related to appetitive motivation. Self-report results indicated that up-regulation increased food craving, which was supported by fMRI results showing that this increase was accompanied by an increase in activity in mesocorticolimbic regions, including the VTA, VS, operculum, PIG, mOFC and vmPFC. Self-report results did not show differences between the cognitive reappraisal and suppression strategy on food craving, but the fMRI results did. Surprisingly, suppression decreased activity in the VTA and VS more successfully than cognitive reappraisal. Both the VTA and the VS play a key role in mediating incentive salience to environmental stimuli that is predictive of behaviorally relevant events (Everitt and Robbins, 2005). This is illustrated by studies showing that lesions or pharmacological manipulation of these two regions prevent the acquisition and expression of Pavlovian approach behavior (Cardinal et al., 2002; Day and Carelli, 2007). The decrease in VTA and VS activity by suppression can therefore be interpreted as the inhibition of the behavioral expression of reward processing. However, results also indicate that suppression increases activity in the bilateral aPFC and dIPFC as compared to cognitive reappraisal, which is in line with the notion that suppression requires increased self-regulatory effort (Gross and John, 2003). An additional observation is that both suppression and cognitive reappraisal resulted in increased activity in the IOFC, while up-regulation resulted in increased activity in the left $\mathrm{VMPFC}$ and the left MOFC. This finding is in line with previous neuroimaging research suggesting that the IOFC, together with the $\mathrm{mOFC} / \mathrm{vmPFC}$, forms separate neural pathways for the up- versus down-regulation of reward (O'Doherty et al., 2001).

The present findings are in line with previous studies indicating that cognitive control strategies can modulate food cravings by changing activity within the mesocorticolimbic circuitry. For example, Kober et al. (2010) showed that the instruction to think about the long-term consequences associated with eating high-fat foods increased activity in prefrontal regions and successfully decreased activity within the striatum. Wang et al. (2009) showed that the instruction to inhibit hunger feelings decreased activity in the VS, insula and OFC, in men but not in women. The present study shows that women can successfully modulate mesocorticolimbic activity related to appetitive motivation by the application of up-regulation, suppression and cognitive reappraisal, and that the specific effects of these strategies on brain activity depend on the type of cognitive control strategy applied: although suppression seems more effective at inhibiting mesocorticolimbic activity compared to cognitive reappraisal as indicated by decreased VS and VTA activity, results also indicate that suppression requires more self-regulatory effort as indicated by the increase in aPFC and dIPFC activity.

The results of this study identify neural mechanisms by which cognitive strategies reduce food craving, and in turn, a potential mechanism by which cognitive therapies can successfully decrease food craving. There is now considerable support that obese people show abnormalities in the mesocorticolimbic circuitry, which - as some researchers believe - may cause them to overeat (Rothemund et al., 2007; Stice et al., 2008; Stoeckel et al., 2008; Volkow and Wise, 2005; Wang et al., 2001). One could argue that the treatment of obesity should target and restore these brain abnormalities. Results of drug treatments targeting mesocorticolimbic neurotransmission (Astrup et al., 2007; Hu et al., 2009) show that they are indeed effective at reducing weight. However, due to their non-specificity, they seem to affect reward processing in general, which increases the risk of adverse psychiatric events (e.g., depression, anxiety, and suicidal ideation). Therefore, it is necessary to find alternative methods to target abnormalities in the mesocorticolimbic circuitry of obese people. One such method may be some form of cognitive behavioral therapy with a focus on training cognitive control strategies such as cognitive reappraisal of palatable foods and suppression of strong food cravings.

A limitation of this study is that the current design cannot test whether suppression or reappraisal significantly lowered subjectively experienced craving compared to passive viewing, because participants were not required to provide subjective craving ratings during passive viewing. As a result we cannot be sure what happened during the passive viewing condition. Although there was no BOLD response in most fROIs, important reward region like the VS, VTA and MOFC did show significant activity during the passive viewing condition. This suggests that some type of reward processing was present during the passive viewing condition. However, without self-reported food craving ratings one cannot be sure whether the observed 
changes in activity were also related to changes in the subjective experience of craving. At the time of designing the experiment it was concluded that asking participants to rate their experienced food craving during the passive viewing condition might bias the participants to focus on the palatability of the presented food stimuli. For that same reason, the passive viewing condition was presented in a separate run; intermixing the passive viewing condition with the other conditions would have the disadvantage of carry-over effects from the cognitive modulation conditions to the passive viewing condition. However, future food craving modulation studies could try to mix the passive viewing task with the cognitive control strategies and have participants rate their food cravings during the passive viewing task to get a baseline measure of subjectively experienced craving.

Another important point to keep in mind, while interpreting the present results, is that the participants in this study were required to apply the cognitive control strategies for only a short time period. There is a great deal of evidence suggesting that control strategies may, in the long run, be counterproductive and even provoke paradoxical overeating (Wardle, 1988). Hofmann et al. (2007) showed that instructing high dietary restrained participants to suppress their emotions while watching an emotional movie clip, significantly increased candy consumption afterwards compared to non-dietary restraint controls and high dietary restrained participants who were allowed to let their emotions flow. In addition, it can be speculated that people with high levels of baseline food craving use more energy when applying cognitive control strategies and are therefore more easily depleted, running the risk of overeating when having to apply these strategies for a longer period of time (e.g. while on a diet), compared to people with low levels of food craving. Future neuroimaging research should therefore focus on the more long-term consequences of cognitive control strategies on mesocorticolimbic activation and identify circumstances in which these processes are compromised.

In conclusion, the present study indicates that healthy women can modulate activity within the mesocorticolimbic circuitry using shortterm cognitive control strategies. This finding is in agreement with previous studies indicating that eating behavior can be successfully inhibited by actively restructuring the way one thinks about foods (Beck, 2007; Stahre and Hallstrom, 2005; Werrij et al., 2009a). The present results provide additional insight into neurobiological mechanisms underlying appetitive motivation, which might aid in development of effective abnormal eating behavior treatment. For example, considering the observed hypoactivity in the PFC of obese individuals (Volkow et al., 2008), one might suppose that they are less effective in suppressing food reward processing. Therefore, cognitive reappraisal might be a more effective strategy. The present findings also indicate that short-term suppression is more effective at directly inhibiting activity in the VTA and VS, the core of the mesocorticolimbic circuitry. It can also be hypothesized that training selfregulatory abilities, for example by training working memory (Hofmann et al., 2008) might increase the ability to effectively inhibit appetitive motivation and restriction of food intake. However, previous research indicates that cognitive control might be highly vulnerable to disruptions (Baumeister, 2002) and may even drain the very resources necessary for their sustainment (Gailliot and Baumeister, 2007). Future research should therefore focus on the long-term consequences of cognitive control strategies on mesocorticolimbic activation and identify circumstances in which these processes are compromised. Present study should be considered as a baseline upon which future studies of cognitive control strategies and their role in modulating corticomesolimbic activation may be compared.

\section{References}

Alcaro, A., Huber, R., Panksepp, J., 2007. Behavioral functions of the mesolimbic dopaminergic system: an affective neuroethological perspective. Brain Res. Rev. 56, 283-321.
Appelhans, B.M., 2009. Neurobehavioral inhibition of reward-driven feeding: implications for dieting and obesity. Obesity 17, 640-647.

Astrup, A. Greenway, F.L. Ling W. Pedicone, L., Lachowicz, J., Strader, C.D., et al, 2007. Randomized controlled trials of the D1/D5 antagonist ecopipam for weight loss in obese subjects. Obesity $15,1717-1731$

Baumeister, R.F., 2002. Ego depletion and self-control failure: an energy model of the self's executive function. Self Identity 1,129-136.

Beck, J., 2007. The Beck Diet Solution. Oxmoor House, Iowa.

Bryant, M., Truesdale, K.P., Dye, L., 2006. Modest changes in dietary intake across the menstrual cycle: implications for food intake research. Br. J. Nutr. 96, 888-894.

Cardinal, R.N., Parkinson, J.A., Lachenal, G., Halkerston, K.M., Rudarakanchana, N., Hall, J., Morrison, C.H., Howes, S.R., Robbins, T.W., Everitt, B.J., 2002. Effects of selective excitotoxic lesions of the nucleus accumbens core, anterior cingulate cortex, and central nucleus of the amygdala on autoshaping performance in rats. Behav. Neurosci. $116,553-567$

Carver, C.S., White, T.L., 1994. Behavioral inhibition, behavioral activation, and affective responses to impending reward and punishment: the BIS/BAS scales. J. Pers. Soc. Psychol. 67, 319-333.

Craig, A.D., 2009. How do you feel-now? The anterior insula and human awareness. Nat. Rev. Neurosci. 10, 59-70.

Davis, C., Patte, K., Levitan, R., Reid, C., Tweed, S., Curtis, C., 2007. From motivation to behaviour: a model of reward sensitivity, overeating, and food preferences in the risk profile for obesity. Appetite 48, 12-19.

Davy, S.R., Benes, B.A., Driskell, J.A., 2006. Sex differences in dieting trends, eating habits, and nutrition beliefs of a group of midwestern college students. J. Am. Diet. Assoc. 106, 1673-1677.

Day, J.J., Carelli, R.M., 2007. The nucleus accumbens and Pavlovian reward learning. Neuroscientist 13, 148-159.

de Araujo, I.E., Rolls, E.T., Velazco, M.I., Margot, C., Cayeux, I., 2005. Cognitive modulation of olfactory processing. Neuron $46,671-679$.

Duzel, E., Bunzeck, N., Guitart-Masip, M., Wittmann, B., Schott, B.H., Tobler, P.N., 2009. Functional imaging of the human dopaminergic midbrain. Trends Neurosci. 32, 321-328

Everitt, B.J., Robbins, T.W., 2005. Neural systems of reinforcement for drug addiction: from actions to habits to compulsion. Nat. Neurosci. 8, 1481-1489.

Friedman, M.I., Ulrich, P., Mattes, R.D., 1999. A figurative measure of subjective hunger sensations. Appetite 32, 395-404.

Gailliot, M.T., Baumeister, R.F., 2007. The physiology of willpower: linking blood glucose to self-control. Pers. Soc. Psychol. Rev. 11, 303-327.

Goldin, P.R., McRae, K., Ramel, W., Gross, J.J., 2008. The neural bases of emotion regulation: reappraisal and suppression of negative emotion. Biol. Psychiatry 63, 577-586.

Goldzieher, J.W., 1994. Are low-dose oral contraceptives safer and better? Am. J. Obstet. Gynecol. 171, 587-590.

Grabenhorst, F., Rolls, E.T., Bilderbeck, A., 2008. How cognition modulates affective responses to taste and flavor: top-down influences on the orbitofrontal and pregenual cingulate cortices. Cereb. Cortex 18, 1549-1559.

Grill-Spector, K., Malach, R., 2001. fMR-adaptation: a tool for studying the functional properties of human cortical neurons. Acta Psychol. 107, 293-321.

Gross, J.J., 2006. Handbook of Emotion Regulation. The Guilfort Press, East Sussex.

Gross, J.J., John, O.P., 2003. Individual differences in two emotion regulation processes: implications for affect, relationships, and well-being. J. Pers. Soc. Psychol. 85, 348-362.

Herman, C.P., Polivy, J., Pliner, P., Threlkeld, J., Munic, D., 1978. Distractibility in dieters and nondieters: an alternative view of "externality". J. Pers. Soc. Psychol. 36, $536-548$.

Hofmann, W., Rauch, W., Gawronski, B., 2007. And deplete us not into temptation: automatic attitudes, dietary restraint, and self-regulatory resources as determinants of eating behavior. J. Exp. Soc. Psychol. 43, 497-504.

Hofmann, W., Gschwendner, T., Friese, M., Wiers, R.W., Schmitt, M., 2008. Working memory capacity and self-regulatory behavior: toward an individual differences perspective on behavior determination by automatic versus controlled processes. J. Pers. Soc. Psychol. 95, 962-977.

Hu, J., Zhu, C., Huang, M., 2009. The endocannabinoid system: a new pharmacological target for obesity treatment? Neurosci. Bull. 25, 153-160.

Kelley, A.E., Berridge, K.C., 2002. The neuroscience of natural rewards: relevance to addictive drugs. J. Neurosci. 22, 3306-3311.

Kober, H., Mende-Siedlecki, P., Krossd, E.F., Weberb, J., Mischelb, W., Hart, C.L., Ochsner, K.N., 2010. Prefrontal-striatal pathway underlies cognitive regulation of craving. Proc. Natl. Acad. Sci. U. S. A. 107, 14811-14816.

Kreitzer, A.C., 2009. Physiology and pharmacology of striatal neurons. Annu. Rev. Neurosci. 32, 127-147.

Moreno, S., Rodriguez, S., Fernandez, M.C., Tamez, J., Cepeda-Benito, A., 2008. Clinical validation of the trait and state versions of the Food Craving Questionnaire. Assessment $15,375-387$

Morse, K.L., Driskell, J.A., 2009. Observed sex differences in fast-food consumption and nutrition self-assessments and beliefs of college students. Nutr. Res. 29, 173-179.

Nederkoorn, C., Smulders, F.T., Havermans, R.C., Roefs, A., Jansen, A., 2006. Impulsivity in obese women. Appetite 47, 253-256.

Nederkoorn, C., Houben, K., Hofmann, W., Roefs, A., Jansen, A., 2010. Control yourself or just eat what you like? Weight gain over a year is predicted by an interactive effect of response inhibition and implicit preference for snack foods. Heal. Psychol. 29, 389-393.

Ochsner, K.N., Ray, R.D., Cooper, J.C., Robertson, E.R., Chopra, S., Gabrieli, J.D., et al., 2004. For better or for worse: neural systems supporting the cognitive downand up-regulation of negative emotion. Neurolmage 23, 483-499. 
O'Doherty, J., Kringelbach, M.L., Rolls, E.T., Hornak, J., Andrews, C., 2001. Abstract reward and punishment representations in the human orbitofrontal cortex. Nat. Neurosci. 4, 95-102.

Rainer, G., Augath, M., Trinath, T., Logothetis, N.K., 2001. Nonmonotonic noise tuning of BOLD fMRI signal to natural images in the visual cortex of the anesthetized monkey. Curr. Biol. 11, 846-854.

Rothemund, Y., Preuschhof, C., Bohner, G., Bauknecht, H.C., Klingebiel, R., Flor, H., et al., 2007. Differential activation of the dorsal striatum by high-calorie visual food stimuli in obese individuals. NeuroImage 37, 410-421.

Saxe, R., Brett, M., Kanwisher, N., 2006. Divide and conquer: a defense of functional localizers. NeuroImage 30, 1088-1096.

Schweinhardt, P., Seminowicz, D.A., Jaeger, E., Duncan, G.H., Bushnell, M.C., 2009. The anatomy of the mesolimbic reward system: a link between personality and the placebo analgesic response. J. Neurosci. 29, 4882-4887.

Siep, N., Roefs, A., Roebroeck, A., Havermans, R., Bonte, M.L., Jansen, A., 2009. Hunger is the best spice: an fMRI study of the effects of attention, hunger and calorie content on food reward processing in the amygdala and orbitofrontal cortex. Behav. Brain. Res. 198, 149-158.

Spinella, M., 2007. Normative data and a short form of the Barratt Impulsiveness Scale. Int. J. Neurosci. 117, 359-368.

Stahre, L., Hallstrom, T., 2005. A short-term cognitive group treatment program gives substantial weight reduction up to 18 months from the end of treatment. A randomized controlled trial. Eat. Weight. Disord. 10, 51-58.

Stephens, M., 2007. Think Slim. Allen \& Unwin, Melbourne.

Stice, E., Spoor, S., Bohon, C., Small, D.M., 2008. Relation between obesity and blunted striatal response to food is moderated by TaqIA A1 allele. Science 322, 449-452.

Stoeckel, L.E., Weller, R.E., Cook III, E.W., Twieg, D.B., Knowlton, R.C., Cox, J.E., 2008 Widespread reward-system activation in obese women in response to pictures of high-calorie foods. NeuroImage 41, 636-647.
Talairach, J., Tournoux, P., 1988. Co-planar Stereotaxic Atlas of the Human Brain. New York.

Volkow, N.D., Wise, R.A., 2005. How can drug addiction help us understand obesity? Nat. Neurosci. 8, 555-560.

Volkow, N.D., Wang, G.J., Telang, F., Fowler, J.S., Thanos, P.K., Logan, J., et al., 2008. Low dopamine striatal D2 receptors are associated with prefrontal metabolism in obese subjects: possible contributing factors. Neurolmage 42, 1537-1543.

Wager, T.D., Davidson, M.L., Hughes, B.L., Lindquist, M.A Ochsner, K.N., 2008. Prefrontal-subcortical pathways mediating successful emotion regulation. Neuron 59 , 1037-1050.

Wang, G.J., Volkow, N.D., Logan, J., Pappas, N.R., Wong, C.T., Zhu, W., et al., 2001. Brain dopamine and obesity. Lancet 357, 354-357.

Wang, G.J., Volkow, N.D., Telang, F., Jayne, M., Ma, Y., Pradhan, K., et al., 2009. Evidence of gender differences in the ability to inhibit brain activation elicited by food stimulation. Proc. Natl. Acad. Sci. U. S. A. 106, 1249-1254.

Wardle, J., 1988. Cognitive control of eating. J. Psychosom. Res. 32, 607-612.

Weiskopf, N., Hutton, C., Josephs, O., Deichmann, R., 2006. Optimal EPI parameters for reduction of susceptibility-induced BOLD sensitivity losses: a whole-brain analysis at $3 \mathrm{~T}$ and $1.5 \mathrm{~T}$. NeuroImage 33, 493-504.

Wenzlaff, R.M., Wegner, D.M., 2000. Thought suppression. Annu. Rev. Psychol. 51, 59-91.

Werrij, M.Q., Jansen, A., Mulkens, S., Elgersma, H.J., Ament, A.J., Hospers, H.J., 2009a. Adding cognitive therapy to dietetic treatment is associated with less relapse in obesity. J. Psychosom. Res. 67, 315-324.

Werrij, M.Q., Roefs, A., Janssen, I., Stapert, D., Wolters, G., Mulkens, S., et al., 2009b. Early associations with palatable foods in overweight and obesity are not disinhibition related but restraint related. J. Behav. Ther. Exp. Psychiatry 40 136-146. 